https://doi.org/10.11606/issn.2317-9511.v34i0p5-26

\title{
Três coleções
}

\section{Three book series}

Denise Bottmann*

Resumo: Este artigo reúne os dados de edição e tradução de três coleções literárias publicadas no Brasil, abrangendo um leque temporal que se estende de 1934 a 1972.

Palavras-chave: História da tradução no Brasil; Coleções; Globo; Mérito; Saraiva.

Abstract: This paper brings together data on the publication and translation of three literary book series in Brazil, covering a time range between 1934 and 1972.

Keywords: History of Translation in Brazil; Book series, Globo; Mérito; Saraiva.

*Historiadora e tradutora. E-mail: dbottmann@gmail.com

TradTerm, São Paulo, v. 34, outubro/2019, p. 5-26 www.revistas.usp.br/tradterm 


\section{Apresentação}

Aqui apresento o levantamento bibliográfico-tradutório de três coleções com duração variada e de razoável a grande importância na história editorial da literatura traduzida no Brasil: a Série Negra, a Seleção Labirinto e a Coleção Saraiva, publicadas respectivamente pela Companhia Editora Nacional, pela Editora Mérito e pela Editora Saraiva.

\section{Série Negra}



A Série Negra - Collecção Policial e de Mysterio, coordenada por Moacyr Deabreu, foi publicada pela Companhia Editora Nacional, de São Paulo. A coleção se estendeu de agosto de 1934 a novembro de 1937,1 apresentando ao todo 24 títulos.

Vale notar que os volumes eram lançados simultaneamente em lotes. Assim, em 13 de julho de 1934, o Diário de Notícias anunciava para breve o

\footnotetext{
${ }^{1}$ Alguns pesquisadores situam a existência da Série Negra de 1934 a 1938 - inclusive nós mesmos, num artigo anterior (KARAM; BOTTMANN 2016: 213). No entanto, a continuidade das pesquisas indica que o último lançamento se deu, no mais tardar, em novembro de 1937. Veja-se o anúncio da coleção completa em Carioca, publicado em página inteira no dia 20 de novembro de 1937.
} 
lançamento de nada menos que oito títulos. De fato, em agosto chegam às livrarias todos os oito volumes iniciais. Transcorreram nove meses até a notícia de lançamento em breve de mais um lote com seis volumes da Série Negra, do 9 ao 14: anunciado em maio, apenas em agosto tem-se a confirmação efetiva do lançamento dessas novas obras. No entanto, o volume 11 , correspondendo a $O$ falsário, apesar de constar nos anúncios de futuro lançamento junto com os demais, por alguma razão sofre um atraso, vindo a sair apenas no começo de 1936 (e por isso o ano vem assinalado em itálico na tabela abaixo). ${ }^{2}$ Nos anos de 1936 e 1937, como comentaremos adiante, é visível o declínio da coleção, com pouquíssimos lançamentos.

Uma característica da coleção era que, desde o início, os anúncios, propagandas e resenhas destacavam como diferencial de qualidade o fato de que as traduções eram feitas "SOMENTE por escriptores". Eis um exemplo: ${ }^{3}$

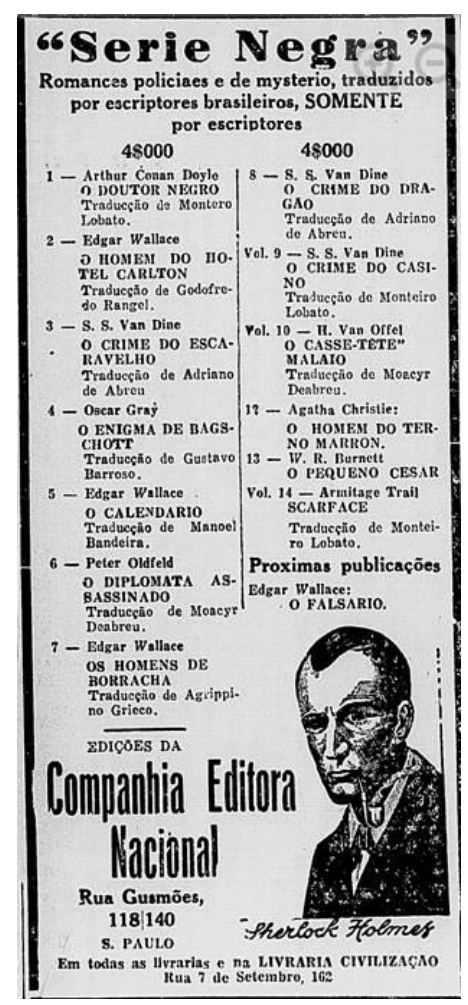

Fonte: Diário de Notícias, 4 de dezembro de 1935

\footnotetext{
${ }^{2}$ Note-se que, de mais a mais, essa obra é a única que consta como lavra de dois tradutores. Isso leva a pensar na hipótese de um atraso ou de uma desistência do tradutor inicial (Waldemar Cavalcanti), cuja tarefa então poderia ter sido transferida para outro (Godofredo Rangel).

${ }^{3}$ Vejam-se outras ocorrências, p.ex.: A Noite, No Mundo do Mysterio e do Crime, 12 de setembro de 1934, e Diário de Notícias, 23 de setembro de 1935.
} 
De fato, até o vigésimo volume as edições traziam o nome do escritortradutor na capa: Monteiro Lobato, Agripino Grieco, Gustavo Barroso, Godofredo Rangel etc. Vejam-se alguns exemplos do padrão das capas sempre em fundo preto, título da obra em destaque, nome do autor, imagem em cores fortes ocupando cerca de metade da área, nome do tradutor com destaque igual ou quase igual ao do nome do autor, nome da editora em corpo menor:

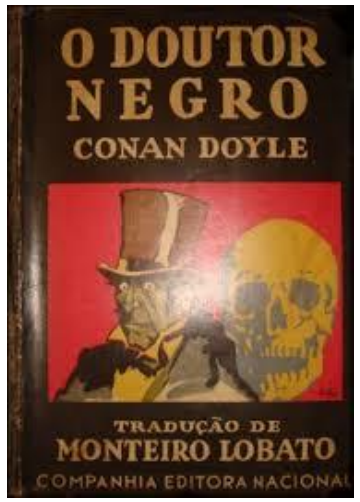

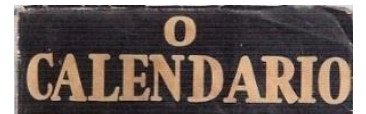
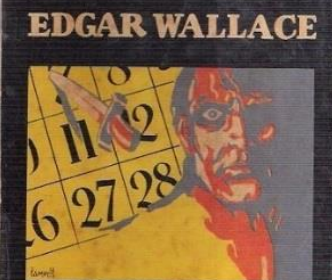

MANOELL BANDEIRA COMPANHIA EDITOPA Macion

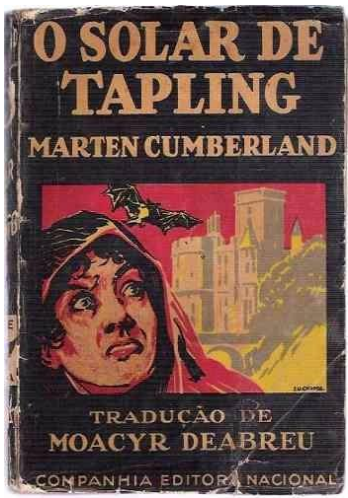

SOLATRI

TAPLING

Padrão de capa até o $20^{\circ}$. volume

Mas em 1937, a partir do vigésimo-primeiro volume, deixa-se de lado a menção ao tradutor na capa. Não é difícil aventar as prováveis razões disso: 0 estranho assassínio de Mr. Artwill era uma novela não de um "escriptor estrangeiro", e sim do alagoano Hildebrando de Lima, escrevendo sob o pseudônimo de “Jack Hall”. A Nacional não chegou ao requinte de apresentála como uma pseudotradução; apenas absteve-se de apresentar os créditos na capa. É curioso notar que, a partir daí, mesmo os volumes subsequentes, do $22^{\circ}$. ao $24^{\circ}$., quando se encerra a coleção, tampouco trazem créditos de tradução na capa, reservando-os apenas para a página de rosto. 




Padrão de capa do $21^{\circ}$. ao $24^{\circ}$. volume

É plausível imaginar que o motivo dessa pequena, mas significativa mudança teria sido a decisão de manter o novo padrão de capa, agora sem créditos de tradução e com o acréscimo do endereço comercial da editora, padrão este que fora inaugurado com a novela brasileira de Hildebrando de Lima. $^{4}$

Outro indício sugestivo presente na listagem da Série Negra é a influência da célebre coleção francesa Le Masque na seleção das obras. Nada menos que nove títulos lançados pela Série Negra haviam sido publicados a partir de 1929 em Le Masque, a saber, os volumes de número 4, 6, 10, 11, 12, 15, 16, 17 e $24 . .^{5}$ Ademais, entre esses volumes nota-se o recurso à interposição do francês para a tradução de algumas obras de língua inglesa. É o caso de $O$ enigma de Bagschott (L'Enigme de Bagschott, do original The Bagschott Mystery), de Oscar Gray, em tradução de Gustavo Barroso; 0 diplomata assassinado (Le Diplomate Assassiné, do original The Death of a Diplomat), de Peter Oldfeld, e O solar de Tapling (Le Manoir de Tapling, do original The Perilous Way), de Marten Cumberland, estes dois em tradução de Moacyr Deabreu; e de Guerra sem piedade (Sans Merci, do original Loaded

\footnotetext{
${ }^{4}$ Irmão do poeta Jorge de Lima, Hildebrando era, naqueles anos, vendedor externo da Livraria Civilização Brasileira, que fora adquirida pela Companhia Editora Nacional em 1932. Foi nessa função que veio a conhecer Monteiro Lobato, que o incentivou a escrever e, muito provavelmente, ofereceu-lhe espaço de publicação na Série Negra. Veja-se sua entrevista "De vendedor de rádios a grande autor de livros para o curso primário", relatando estes e outros fatos, em A Manhã, 15 de março de 1947. As duas outras novelas de crime e mistério que Hildebrando de Lima escreveu sob o pseudônimo de Jack Hall - Os Assassínios do Castello Saint Denis e $O$ crime dos três inocentes - foram publicadas diretamente pela Civilização Brasileira, em suas Edições SIP, Collecções Economicas, respectivamente em 1937 e 1940.

${ }^{5}$ Para a listagem das obras publicadas na coleção Le Masque, ver Wikipedia, "Liste des ouvrages publiés dans Le Masque".
} 
Dice), também de Marten Cumberland, cuja tradução sabemos apenas que foi "revista por Godofredo Rangel" - também responsável, diga-se de passagem, por "rever" a tradução de outros dois volumes, o 15 e o 16, estes de língua francesa.

\begin{tabular}{|c|c|c|c|c|}
\hline Autor & Título & Tradutor & V. & Ano \\
\hline Doyle, A. Conan & O doutor negro & Monteiro Lobato & 1 & 1934 \\
\hline Wallace, Edgar & $\begin{array}{l}\text { O homem do Hotel } \\
\text { Carlton }\end{array}$ & Godofredo Rangel & 2 & 1934 \\
\hline Van Dine, S.S. & O crime do escaravelho & Adriano de Abreu & 3 & 1934 \\
\hline Gray, Oscar & O enigma de Bagschott & Gustavo Barroso & 4 & 1934 \\
\hline Wallace, Edgar & O calendário & Manuel Bandeira & 5 & 1934 \\
\hline Oldfeld, Peter & O diplomata assassinado & Moacyr Deabreu & 6 & 1934 \\
\hline Wallace, Edgar & Os homens de borracha & Agripino Grieco & 7 & 1934 \\
\hline Van Dine, S.S. & O crime do dragão & Adriano de Abreu & 8 & 1934 \\
\hline Van Dine, S.S. & O crime do cassino & Monteiro Lobato & 9 & 1935 \\
\hline Van Offel, Horace & O cassetete malaio & Moacyr Deabreu & 10 & 1935 \\
\hline Walla & O falsário & $\begin{array}{l}\text { Waldemar } \\
\text { Cavalcanti } \\
\text { Godofredo Rangel }\end{array}$ & 11 & 1936 \\
\hline Christie, Agatha & $\begin{array}{l}\text { O homem do terno } \\
\text { marrom }\end{array}$ & Moacyr Deabreu & 12 & 1935 \\
\hline Burnett, W.E. & O pequeno César & Monteiro Lobato & 13 & 1935 \\
\hline Trail, Armitage & Scarface & Monteiro Lobato & 14 & 1935 \\
\hline Boucard, Robert & $\begin{array}{l}\text { Os mistérios dos } \\
\text { arquivos secretos }\end{array}$ & $\begin{array}{l}\text { Trad. revista por } \\
\text { Godofredo Rangel }\end{array}$ & 15 & 1935 \\
\hline Boucard, Robert & O Intelligence Service & $\begin{array}{l}\text { Trad. revista por } \\
\text { Godofredo Rangel }\end{array}$ & 16 & 1935 \\
\hline $\begin{array}{l}\text { Cumberland, } \\
\text { Marten }\end{array}$ & O solar do Tapling & Moacyr Deabreu & 17 & 1935 \\
\hline Van Dine, S.S. & O caso Garden & Monteiro Lobato & 18 & 1935 \\
\hline Hammett, Dashiell & A ceia dos acusados & Monteiro Lobato & 19 & 1936 \\
\hline Wallace, Edgar & A porta dos traidores & Godofredo Rangel & 20 & 1936 \\
\hline $\begin{array}{l}\text { Hall, Jack [pseud. } \\
\text { de Hildebrando de } \\
\text { Lima] }\end{array}$ & $\begin{array}{l}\text { O estranho assassínio de } \\
\text { Mr. Artwill }\end{array}$ & & 21 & 1937 \\
\hline Rohmer, Sax & O presidente Fu-Manchu & Godofredo Rangel & 22 & 1937 \\
\hline MacDonald, Philip & R.I.P. ou A data fatal & Azevedo Amaral & 23 & 1937 \\
\hline $\begin{array}{l}\text { Cumberland, } \\
\text { Marten }\end{array}$ & Guerra sem piedade & $\begin{array}{l}\text { Trad. revista por } \\
\text { Godofredo Rangel }\end{array}$ & 24 & 1937 \\
\hline
\end{tabular}


Há de se notar a escassez de lançamentos em 1936 - apenas três títulos, um deles, aliás, previsto para 1935 e adiado para o ano seguinte ( $O$ falsário), como já comentamos. E aqui é o momento de mencionarmos rapidamente um detalhe: The Thin Man, de Dashiell Hammett, foi lançado em 1936 com seu título traduzido por A ceia dos acusados - como não é raro encontrar críticas a essa escolha, atribuindo-a a alguma excessiva liberdade de Monteiro Lobato, vale lembrar que foi este o nome utilizado para o filme de Van Dyke, estrelado por Tyrone Power e Myrna Loy, em seu lançamento brasileiro em 1934. Seu grande sucesso é, a meu ver, o que justifica a escolha do mesmo nome para o título brasileiro adotado na Série Negra.

Prosseguindo: em 1936 nota-se que a divulgação na imprensa cai radicalmente, reduzindo-se a pouquíssimos anúncios. A escassez de novos títulos prossegue em 1937, e em novembro tem-se o encerramento das publicações da Série Negra.

Mesmo as vendas dos títulos publicados não parecem ter sido muito exitosas: a partir de julho de 1939, a Nacional promove uma liquidação dos volumes, com venda pela metade do preço: se antes, desde 1934, cada volume em brochura saía a 4 mil-réis, agora a coleção está à venda por 2 milréis cada volume. A promoção continua pelo menos até o mês de outubro.

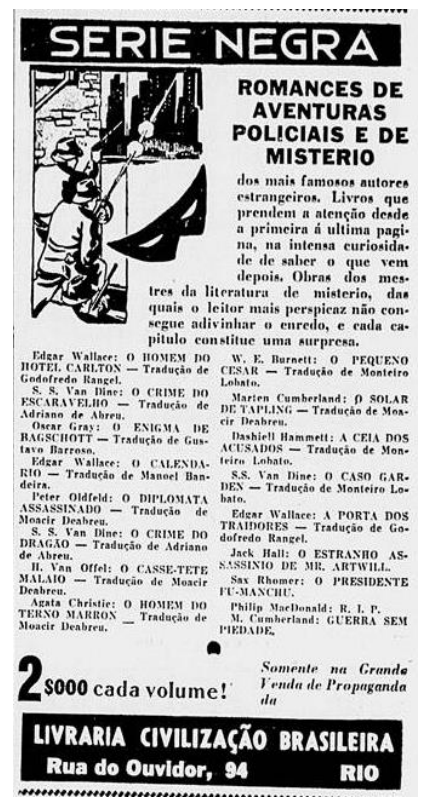

A Noite, 16 de outubro de 1939 
Note-se, porém, que são anunciados dezessete dos 24 títulos publicados. Os outros sete títulos - $O$ doutor negro, Os homens de borracha, O crime do cassino, o falsário, Scarface, Os mistérios dos arquivos secretos e O Intelligence Service -, teriam eles se esgotado? Difícil saber.

Por fim, registre-se a ocorrência de pelo menos duas serializações de obras publicadas na Série Negra. A primeira foi $O$ homem de terno marrom, que sairia em livro a partir de setembro de 1935, serializada no Diário de Notícias a partir de 30 de dezembro de 1934 em 36 episódios, estendendo-se até 12 de fevereiro de 1935. A segunda é $O$ caso Garden, publicada na coleção em 1935 e serializada a partir de 10 de agosto de 1936 no Diário da Noite.

\section{Seleção Labirinto}



Em 1953, a Editora Mérito, casa editorial paulista já solidamente estabelecida na época, promoveu a criação de um clube de leitura entre seus assinantes e clientes domiciliares, patrocinado por seu Clube do Mês. Chamava-se Clube de Novelas Labirinto, concentrando-se basicamente, embora não exclusivamente, em novelas estrangeiras de crime, suspense e mistério. Os membros podiam escolher mensalmente dois romances policiais selecionados pelo clube. Assim, embora de início os volumes fossem identificados na capa como integrantes do "Clube de Novelas Labirinto", logo a seguir passou-se a apresentá-los sob a égide de "Uma Seleção Labirinto", numa tarja impressa nas edições em brochura e numa gravação nas edições em capa dura, sendo também distribuídos em livrarias. Mais tarde, o próprio padrão de capa foi alterado, passando a consistir em retângulos cromáticos: branco, amarelo, vermelho e azul. 

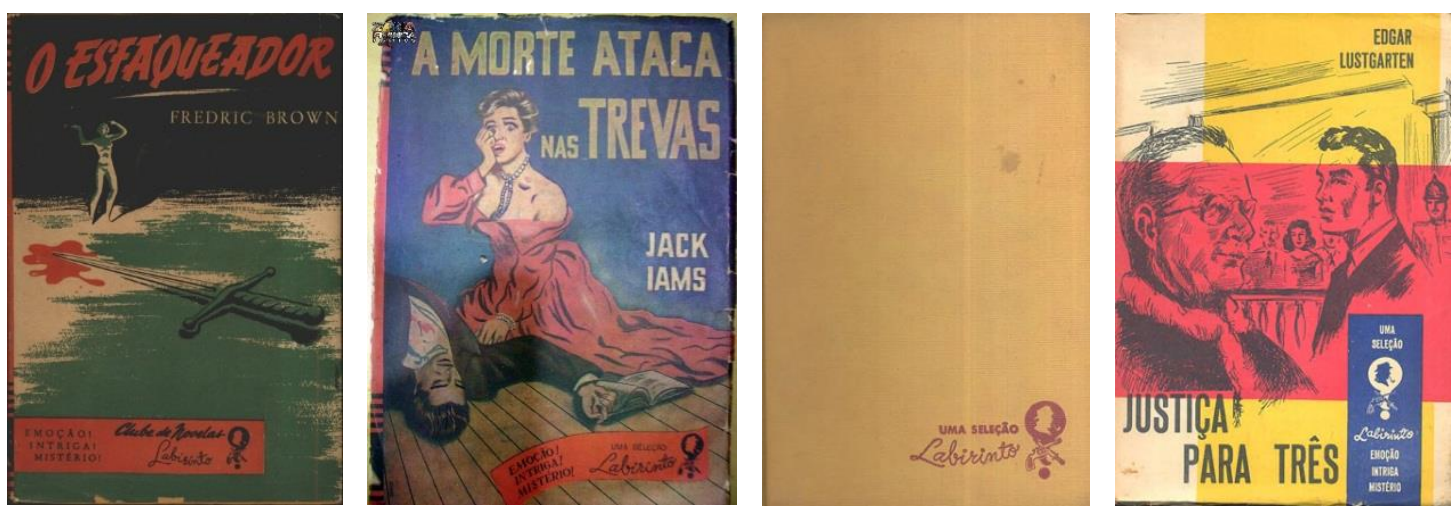

Padrões de capa

A coleção foi lançada no mês de maio de 1953, com anúncios publicados pela editora nos jornais Folha da Manhã, Correio da Manhã e Diário de Notícias. Na ocasião, O Jornal deu uma nota informando sobre o início da coleção. O primeiro par de volumes - ou "dupla seleção”, como dizia a editora - era constituído por $O$ esfaqueador, de Fredric Brown, e Nó mortal, de Mary McMullen. Ao longo do ano saíram mais dois ou três anúncios com notícia de novos lançamentos, sempre com o oferecimento de um volume de brinde no ato de inscrição.

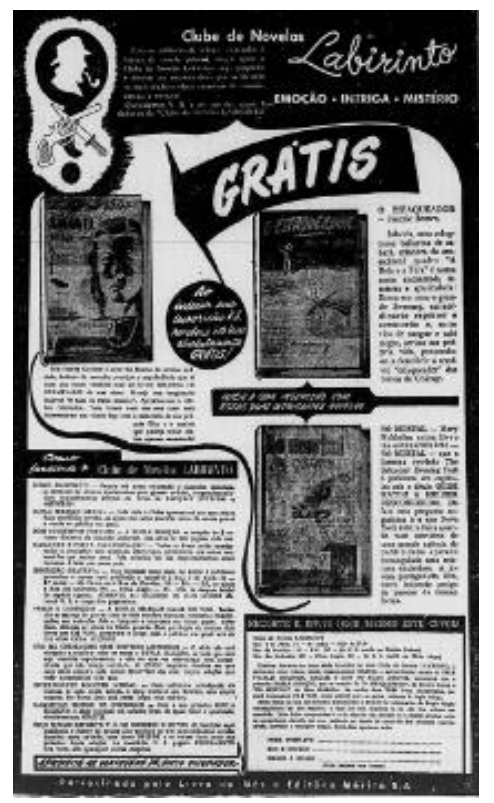

Diário de Notícias, 24 de maio de 1953

Embora fosse uma coleção com dois lançamentos por mês, apenas em outubro de 1953 é que encontramos notícia de novas edições. Em mais dois 
anúncios, um na Folha da Manhã e outro no Diário de Notícias (em dimensões sempre um pouco menores vez a vez), informa-se que saíram dois outros lançamentos: Quem matou a milionária?, de Rex Stout, e Aluga-se um cemitério, de Carter Dickson, sempre com $O$ caso do falso amante como brinde para os novos assinantes. A última referência aos duplos lançamentos da Labirinto que encontrei na imprensa foi uma propaganda na revista $O$ Cruzeiro, em janeiro de 1954, anunciando $O$ desconhecido de olhos pretos, de Charlotte Armstrong, e A trágica noite de estreia, de Ngaio Marsh; O coquetel da morte, de Lawrence Blochman, e A grande retina, de Max Ehrlich; Marcas de pés no teto, de Clayton Rawson, e Um cadáver misterioso, de Erle Stanley Gardner. Dessa feita, o livro de cortesia era $O$ esfaqueador, de Fredrick Brown, que fizera parte do primeiro par publicado.

O Clube de Novelas Labirinto se estendeu de 1953 a 1956, provavelmente com alguns intervalos irregulares na periodicidade prometida e, como comentamos, cada vez mais escassa divulgação nos meios de comunicação. Como foram publicados cinquenta títulos, o que abasteceria apenas dois anos e um mês de subscrição, parece-me plausível supor que a iniciativa não teve o retorno esperado, levando ao encerramento da coleção.

Paulo de Medeiros e Albuquerque, em seu alentado estudo sobre 0 mundo emocionante do romance policial, arrola 49 volumes publicados pela Mérito nessa coleção (1979: 339-344) e comenta ter notícias sobre a existência de um quinquagésimo volume, ao qual, porém, não conseguiu ter acesso (1979: 344). Provavelmente trata-se de $A$ morte ataca nas trevas, de Jack lams, ausente de seu levantamento e lançado em 1954. A listagem elaborada por Medeiros e Albuquerque traz o nome do autor, os títulos do original e da tradução, e a especificação se a edição vinha em capa dura ou brochura. Não constam, porém, os respectivos anos de edição nem os nomes dos tradutores. São esses dados - quando saiu; quem traduziu - que tentarei suprir, utilizando como base o arrolamento de Medeiros e Albuquerque.

\subsection{Volumes publicados}

Armstrong, Charlotte, O desconhecido de olhos pretos. Trad. B. A. Prado, 1953 
Blochman, Lawrence, O coquetel da morte. Trad. Olga Biar Laino, 1953

Brown, Fredric, O esfaqueador. Trad. B. A. Prado, 1953

Canning, Victor, A casa das sete moscas. Trad. Jacó Guinsburg, 1955. , Pássaro veneziano. Trad. Leonor de Aguiar, 1954

Carr, John Dickson, O castelo da caveira. Trad. B. A. Prado, 1953

Coles, Manning, A sombra do enforcado. Trad. Pedro Henrique, 1954 , Noturno para Paris. Trad. Olga Biar Laino, 1954

Davis, Frederick C., Qual delas teria sido? Trad. José Geraldo Vieira, 1955

Dickson, Carter, Aluga-se um cemitério. Trad. Flávio Amarante, 1953

Dodge, David, A ovelha negra. Trad. Pedro Henrique, 1953 , O gato na armadilha. Trad. Olga Biar Laino, 1953

Ehrlich, Max, A grande retina. Trad. José Geraldo Vieira, 1953 Gardner, Erle Stanley, A Vênus do bairro chinês. Trad. José Geraldo Vieira, 1956

, O caso da donzela errante. Trad. Olga Biar Laino, 1955 , O caso da irmã de olhos verdes. Trad. José Geraldo Vieira, 1956 , O caso da testemunha caolha. Trad. J. de S. Pacheco, 1955 , O caso das drogas entorpecentes. Trad. Carlos Chaves, 1955 , O caso do casaco de peles. Trad. Leonor de Aguiar, 1954 , O caso do falso amante. Trad. Leonor de Aguiar, 1953 , O caso dos dedos luminosos. Trad. Lígia Junqueira, 1954 , O sorriso do gorila. Trad. Lígia Junqueira, 1954 , Um cadáver misterioso. Trad. Carlos Chaves, 1953 , Um caso de bigamia. Trad. Oscar Mendes, 1955 Halliday, Brett, O mistério do espia. Trad. Olga Biar Laino, 1954 Hitchens, Dolores, Escada para um quarto vazio. Trad. Leonor de Aguiar, 1954 lams, Jack, A morte ataca nas trevas. Trad. Nair Lacerda, 1954 , Lua-de-mel entre crimes. Trad. Pedro Henrique, 1953 Lockridge, Richard \& Frances, A morte fala baixinho. Trad. Virginia Lefèvre, 1956 , Conspiração na Flórida. Trad. Virginia Lefèvre, 1956 , Solteironas em pânico. Trad. B. A. Prado, 1953 Loraine, Philip, A cidade do pesadelo. Trad. Pedro Henrique, 1954 
Lustgarten, Edgar, Justiça para três. Trad. Olga Biar Laino, 1954

Marsh, Ngaio, A trágica noite de estreia. Trad. Nair Lacerda, 1953

McMullen, Mary, Nó mortal. Trad. Leonor de Aguiar, 1953

Queen, Ellery, O rei está morto. Trad. Jerônimo Monteiro, 1955

Quentin, Patrick, A viúva negra. Trad. Oscar Mendes, 1955

Rawson, Clayton, Marcas de pés no teto. Trad. Pedro Henrique, 1953

Rinehart, Mary Roberts, A faca misteriosa e outros contos. Trad. B. A. Prado, 1953

Seeley, Mabel, O lago do terror. Trad. Olga Biar Laino, 1953

Stout, Rex, A cadeia de crimes. Trad. Olga Biar Laino, 1955

, A novela assassina. Trad. Jacó Guinsburg, 1954

, A pista dos três alçapões. Trad. José Geraldo Vieira, 1955

, Quem matou a milionária? Trad. B. A. Prado, 1953

, Três portas para a morte. Trad. Leonor de Aguiar, 1954

, Trilogia de mistério. Trad. Olga Biar Laino, 1954

Teilhet, Hildegard, Carnaval de sangue. Trad. Olga Biar Laino, 1954

Walsh, Thomas, O assassino usava emblema. Trad. G. D. Landau, 1955

York, Jeremy, Anjo e demônio. Trad. Olga Biar Laino, 1955

$\mathrm{Na}$ listagem acima, nota-se um elemento interessante: a presença de Rex Stout, cujas novelas recebem impulso no Brasil justamente na Seleção Labirinto. 0 autor americano chegara a nós pela primeira vez em 1950, com $A$ caixa vermelha (The Red Box) em tradução de Isaac Soares, como volume 140 da Coleção Amarela, da Livraria do Globo. Ainda que Erle Stanley Gardner tenha sido o autor mais publicado na Seleção Labirinto, com onze títulos, o aspecto a levar em conta é que Gardner já era bastante conhecido no Brasil, sobretudo pelas publicações da já citada Coleção Amarela, da Livraria do Globo, ao passo que Rex Stout era praticamente inédito. Assim, podemos considerar que foi a Seleção Labirinto que promoveu sua divulgação entre nós, publicando entre 1953 e 1955 nada menos que seis títulos de Rex Stout. 


\section{Coleção Saraiva}

\section{Caleçãa Saraiva}

Em 1948, a Editora Saraiva deu início a uma coleção mensal de literatura, a Coleção Saraiva, com obras de autores nacionais e estrangeiros. Os livros eram publicados em brochuras simples a preço bastante acessível, com comercialização feita pelo sistema de venda domiciliar e subscrição. Entre julho de 1948 e maio de 1972, saíram pela Coleção Saraiva nada menos que 232 obras, algumas delas em dois ou mais volumes, totalizando 287 volumes, em tiragens que chegavam a 50 mil exemplares por edição. Diversos títulos foram reeditados ao longo dos anos dentro da própria coleção, que se mostrou de grande longevidade.

Aqui arrolo apenas as obras traduzidas da coleção, com o número do volume correspondente, e apresento os respectivos créditos de tradução. ${ }^{6}$ Como se verá, no notável elenco de tradutores atuantes na Coleção Saraiva que incluía José Geraldo Vieira, Paulo Rónai, J. B. Mello e Souza, Miroel Silveira, Isa Silveira Leal e Ondina Ferreira -, destacam-se três nomes responsáveis pela grande maioria das traduções: em primeiro lugar Augusto de Sousa, ${ }^{7}$ com nada menos que 29 obras em 48 volumes, seguido por Nair Lacerda, com 25 obras em 26 volumes, e Octavio Mendes Cajado, com 11 obras em 20 volumes.

Alguns dos títulos já haviam sido lançados anteriormente, ao passo que outros foram reeditados posteriormente, em outras coleções ou no catálogo

\footnotetext{
${ }^{6}$ Tomei como base a listagem completa de obras nacionais e estrangeiras (porém sem os créditos de tradução) disponível no blog Listas de Livros, "Coleção Saraiva". Disponível em: < https://listasdelivros.blogspot.com/2013/12/colecao-saraiva-editora-saraiva-1948.html>. Acesso em: 27 jun. 2019. Também encontra-se algum material iconográfico no blog Boa Leitura para Vocês!, "Coleção Saraiva". Disponível em: $<$ http://boaleituraparavoces.blogspot.com/search/label/Cole\%C3\%A7\%C3\%A30\%20Saraiva >. Acesso em: 27 jun. 2019.

${ }^{7}$ A grafia varia muito: Augusto Sousa, Augusto de Sousa, Augusto Souza, Augusto de Souza. Adotamos aqui Augusto de Sousa, aparentemente o de uso mais frequente.
} 
geral da editora. Esses casos, quando foram localizados, vêm informados na relação abaixo.

\subsection{Traduções publicadas}

005. Lewis Wallace, Ben-Hur, Romance dos tempos de Jesus Cristo, trad. J. B. de Souza [João Baptista de Mello e Souza] (nov. 1948)

007. Fiódor Dostoiévski, Recordações da casa dos mortos, trad. José Geraldo Vieira (jan. 1949) - reed. Coleção Jabuti, 1958, em 2 vols.

012. Henryk Sienkiewicz, Quo vadis?, trad. J.B. de Souza (jun. 1949) - reed. Coleção Jabuti, 1952

016. H. G. Wells, O alimento dos deuses, "Tradução sob responsabilidade da Coleção Saraiva e da Editora Saraiva" (out. 1949) ${ }^{8}$

018. Lord Lytton, Os últimos dias de Pompeia, trad. e adapt. Miroel da Silveira e Isa Silveira Leal (dez. 1949)

020. Edna Ferber, Cimarron, trad. Nair Lacerda (fev. 1950) - reed. Coleção Jabuti, 1952

022. Alphonse Daudet, $A$ borboleta azul, trad. José Geraldo Vieira (abr. 1950) - reed. Coleção Jabuti, 1952

023. Zofia Kossak, O santo sepulcro, trad. Isa Silveira Leal e Miroel Silveira (maio 1950)

024. Edmond About, $O$ homem da orelha rasgada, trad. Octavio Mendes Cajado (jun. 1950)

026. Giovanni Papini, Testemunhas da Paixão, trad. Nair Lacerda (ago. 1950) - reed. Coleção Jabuti, 1957, 1960; Tecnoprint/Clássicos de Ouro, s/d 027. Barbey D'Aurevilly, Os conspiradores, trad. Octavio Mendes Cajado (set. 1950)

028. Lawrence Edward Watkin, Horas roubadas, trad. Nair Lacerda (out. 1950) 029. Germaine Acremant, A vida que sonhei, trad. Octavio Mendes Cajado (nov. 1950)

031. Erckman-Chatrian, O recruta de Napoleão, trad. Augusto de Sousa (jan. 1951) - reed. Coleção Jabuti, 1955

\footnotetext{
${ }^{8}$ Não sei o que significa essa atribuição. Vale notar, porém, que a Livraria Clássica Editora, de Portugal, lançara $O$ alimento dos deuses em 1909, em tradução de Manuel de Macedo.
} 
035. Robert Nathan, Depois do verão, trad. Nair Lacerda (maio 1951)

036. Henryk Sienkiewicz, O campo da glória, trad. Mariano Torres (jun. 1951)

039. Victor Cherbuliez, A máscara da face, trad. Nair Lacerda (set. 1951)

041. Hermann Sudermann, O moinho silencioso, trad. Nair Lacerda (nov. 1951)

044. Erckmann-Chatrian, Waterloo, trad. Augusto de Sousa (fev. 1952) reed. Coleção Jabuti, 1958

045. Honoré de Balzac, Pierrette, trad. Nair Lacerda (mar. 1952)

046. Alexandre Dumas, Nero, trad. Octavio Mendes Cajado (abr. 1952)

048. Mark Aldanov, A glória de Byron, trad. Nair Lacerda (jun. 1952)

052. Hermann Melville, Dramas do mar [com Benito Cereno e Billy Budd], trad. Octavio Mendes Cajado (out. 1952)

054. Francisco Molnar, Os meninos da rua Paulo, trad. Paulo Rónai (dez. 1952) - reed. Coleção Jabuti, 1973

055. Alexandre Dumas, A tulipa negra, trad. Augusto de Sousa (jan. 1953)

057. Walter Scott, Lúcia de Lammermoor, trad. Hamilcar de Garcia (mar. 1953)

059. Paul Vialar, Amor de mãe, trad. Augusto de Sousa (maio 1953)

060. Júlio Verne, Miguel Strogoff, vol. 1, trad. Augusto de Sousa (jun. 1953)

061. Júlio Verne, Miguel Strogoff, vol. 2, trad. Augusto de Sousa (jul. 1953)

064. Louisa May Alcott, As quatro irmãs, trad. Nair Lacerda (out. 1953)

065. George Sand, Os gêmeos, trad. Augusto de Sousa (nov. 1953)

066. Charles Dickens, O grilo da lareira, trad. Aldo della Nina (dez. 1953)

069. Júlio Verne, As tribulações de um chinês na China, trad. Augusto de Sousa (mar. 1954)

074. Charles \& Mary Lamb, Contos de Shakespeare, vol. 1, trad. Octavio Mendes Cajado (ago. 1954)

075. Charles \& Mary Lamb, Contos de Shakespeare, vol. 2, trad. Octavio Mendes Cajado (set. 1954)

076. Alexandre Dumas, Os irmãos corsos, trad. Augusto de Sousa (out. 1954)

080. Amédée Achard, $O$ capitão Belle-Rose, vol. 1, trad. Augusto de Sousa (fev. 1955)

081. Amédée Achard, 0 capitão Belle-Rose, vol. 2, trad. Augusto de Sousa (mar. 1955) 
082. Henry James, A herdeira, trad. Ondina Ferreira (abr. 1955)

083. Ivan Turguêniev, Vida nova, trad. Ondina Ferreira (maio 1955)

084. Oliver Goldsmith, $O$ vigário de Wakefield, trad. Nair Lacerda (jun. 1955)

085. Alexandre Dumas, $O$ salteador, trad. Ondina Ferreira (jul. 1955)

087. Charles Kingsley, Os heróis, trad. Ondina Ferreira (set. 1955)

088. Franca Lenardon, Uma mulher, trad. Aldo della Nina (out. 1955)

090. Fritz Erckmann-Chatrian, $O$ amigo, trad. Augusto de Sousa (dez. 1955)

092. Paul Féval, Os mistérios de Londres, vol. 1, trad. Augusto de Sousa (fev. 1956)

093. Paul Féval, Os mistérios de Londres, vol. 2, trad. Augusto de Sousa (mar. 1956)

094. Alexandre Dumas, Othon, o archeiro, trad. Augusto de Sousa (abr. 1956)

096. Amédée Archad, Capa e espada, vol. 1, trad. Augusto de Sousa (jun. 1956)

097. Amédée Archad, Capa e espada, vol. 2, trad. Augusto de Sousa (jul. 1956)

098. Amédée Archad, $O$ tosão de ouro, vol. 1, trad. Augusto de Sousa (ago. 1956)

099. Amédée Archad, O tosão de ouro, vol. 2, trad. Augusto de Sousa (set. 1956)

100. Robert Louis Stevenson, $A$ ilha do tesouro, trad. Nair Lacerda (out. 1956)

102. Tom Galt, Peter Zenger, campeão da liberdade, trad. Ondina Ferreira (dez. 1956)

103. Voltaire, Zadig, trad. Augusto de Sousa (jan. 1957)

104. Louisa May Alcott, Esposas exemplares, trad. Nair Lacerda (fev. 1957)

107. Honoré de Balzac, O coronel Chabert, trad. rev. Pedro Reis (maio 1957)

109. Nathaniel Hawthorne, A letra escarlate, trad. A. Pinto de Carvalho (jul. 1957)

112. Eugène Sue, $O$ comendador de Malta, trad. Alberto Denis (out. 1957)

113. Ralph Moody, Kit Carson e a fronteira selvagem, trad. Nair Lacerda (nov. 1957)

114. Théophile Gautier, Avatar, trad. Nair Lacerda (dez. 1957)

117. Júlio Verne, Cinco semanas em balão, trad. Augusto de Sousa (mar. 1958) 
118. Emily Brontë, O Morro dos Ventos Uivantes, vol. 1, trad. Octavio Mendes Cajado (abr. 1958)

119. Emily Brontë, O Morro dos Ventos Uivantes, vol. 2, trad. Octavio Mendes Cajado (maio 1958)

122. Massimo D'Azeglio, Ettore Fieramosca, trad. Alberto Denis (ago. 1958)

123. Oscar Wilde, O fantasma de Canterville e outras histórias, trad. Nair Lacerda (set. 1958)

124. Anna Sewell, Beleza negra, trad. Nair Lacerda (out. 1958)

126. Albert Pigelow Paine, Mark Twain, trad. Nair Lacerda (dez. 1958)

130. Conrad Ferdinand Meyer, Assassínio na catedral, trad. Alberto Denis (abr. 1959)

131. Georg Ebers, Cleópatra, vol. 1, trad. Alberto Denis (maio 1959)

132. Georg Ebers, Cleópatra, vol. 2, trad. Alberto Denis (jun. 1959)

134. Helen Hunt Jackson, Ramona, vol. 1, trad. Alberto Denis (ago. 1959)

135. Helen Hunt Jackson, Ramona, vol. 2, trad. Alberto Denis (set. 1959)

136. Wilkie Collins, Dois destinos, trad. Nair Lacerda (out. 1959)

138. Alphonse Daudet, Tartarin de Tarascon, trad. Nair Lacerda (dez. 1959)

143. Robert Louis Stevenson, $O$ médico e o monstro e outras histórias ["Markheim" e "O diabrete da garrafa"], trad. Nair Lacerda (maio 1960)

146. Amédée Achard, As cutiladas do Conde de La Guerche, vol. 1, trad. Augusto de Sousa (ago. 1960)

147. Amédée Achard, As cutiladas do Conde de La Guerche, vol. 2, trad. Augusto de Sousa (set. 1960)

148. Amédée Achard, Contra tudo e contra todos, vol. 1, trad. Augusto de Sousa (out. 1960)

149. Amédée Achard, Contra tudo e contra todos, vol. 2, trad. Augusto de Sousa (nov. 1960)

150. Ivan Turguêniev, Primeiro amor, trad. Nair Lacerda (dez. 1960)

157. Émile Gaboriau, O caso Lerouge, vol. 1, trad. Augusto de Sousa (jul. 1961)

158. Émile Gaboriau, O caso Lerouge, vol. 2, trad. Augusto de Sousa (ago. 1961) 
159. Edgar Allan Poe, Os crimes da rua Morgue e outras histórias, trad. Aldo della Nina (set. 1961)

169. George Harmon Coxe, Sedutor de mulheres, trad. Nair Lacerda (jul. 1962) - ed. Coleção Cinzenta, 1952

170. Edna Ferber, Teatro flutuante, vol. 1, trad. Nair Lacerda (ago. 1962) ed. Coleção Arco-Íris, 1950 (inaugura a coleção)

171. Edna Ferber, Teatro flutuante, vol. 2, trad. Nair Lacerda (set. 1962) ed. Coleção Arco-Íris, 1950

173. Harriet Beecher Stowe, A cabana do Pai Tomás, vol. 1, trad. Octavio Mendes Cajado (nov. 1962) - ed. Série Ouro e Prata (1951)

174. Harriet Beecher Stowe, A cabana do Pai Tomás, vol. 2, trad. Octavio Mendes Cajado (dez. 1962) - ed. Série Ouro e Prata (1951)

177. Konrad Bercovici, A terra prometida, vol.1, trad. José Geraldo Vieira (mar. 1963) - ed. Coleção Arco-Íris, vol. 2, 1950

178. Konrad Bercovici, A terra prometida, vol. 2, trad. José Geraldo Vieira (abr. 1963) - ed. Coleção Arco-Íris, vol. 2, 1950

184. Leon Tolstoi, A morte de Ivan Ilitch, trad. Gulnara Lobato de Moraes (out. 1963) - 1948

187. George Ohnet, $O$ grande industrial, trad. Augusto de Sousa (jan. 1964)

195. Honoré de Balzac, O tio Goriot, vol. 1, trad. Augusto de Sousa (set. 1964)

196. Honoré de Balzac, 0 tio Goriot, vol. 2, trad. Augusto de Sousa (out. 1964)

201. Alexandre Dumas, Os três mosqueteiros, vol. 1, trad. Octavio Mendes Cajado (mar. 1965) - Romances de Alexandre Dumas, 1959 (em 2 vols.)

202. Alexandre Dumas, Os três mosqueteiros, vol. 2, trad. Octavio Mendes Cajado (abr. 1965) - Romances de Alexandre Dumas, 1959 (em 2 vols.)

203. Alexandre Dumas, Os três mosqueteiros, vol. 3, trad. Octavio Mendes Cajado (mai. 1965) - Romances de Alexandre Dumas, 1959 (em 2 vols.)

204. Alexandre Dumas, Os três mosqueteiros, vol. 4, trad. Octavio Mendes Cajado (jun. 1965) - Romances de Alexandre Dumas, 1959 (em 2 vols.)

206. Cícero, Dos deveres, trad. João Mendes Neto (ago. 1965)

212. Alphonse Daudet, Cartas do meu moinho, trad. Augusto de Sousa (fev. 1966) 
214. Alexandre Dumas, Cecília, trad. Augusto de Sousa (abr. 1966)

216. Enrique Perez Escrich, O mártir do Gólgota - tradições do Oriente, vol.

1, trad. Augusto de Sousa (jun. 1966) - Coleção Ouro e Prata, [1957]

217. Enrique Perez Escrich, O mártir do Gólgota - tradições do Oriente, vol.

2, trad. Augusto de Sousa (jul. 1966)

218. Enrique Perez Escrich, O mártir do Gólgota - tradições do Oriente, vol. 3, trad. Augusto de Sousa (ago. 1966)

219. Enrique Perez Escrich, O mártir do Gólgota - tradições do Oriente, vol. 4, trad. Augusto de Sousa (set. 1966)

220. Plutarco, Vida de Júlio César, não consta crédito de trad. (out. 1966)

224. Alexandre Dumas, A conquista de Nápoles, vol. 1, trad. Augusto de Sousa (fev. 1967)

225. Alexandre Dumas, A conquista de Nápoles, vol. 2, trad. Augusto de Sousa (mar. 1967)

226. Alexandre Dumas, A conquista de Nápoles, vol. 3, trad. Augusto de Sousa (abr. 1967)

227. Alexandre Dumas, A conquista de Nápoles, vol. 4, trad. Augusto de Sousa (mai. 1967)

232. Lewis Wallace, 0 príncipe da Índia, vol. 1, trad. Octavio Mendes Cajado (out. 1967)

233. Lewis Wallace, 0 príncipe da Índia, vol. 2, trad. Octavio Mendes Cajado (nov. 1967)

234. Lewis Wallace, O príncipe da Índia, vol. 3, trad. Octavio Mendes Cajado (dez. 1967)

235. Lewis Wallace, 0 príncipe da Índia, vol. 4, trad. Octavio Mendes Cajado (jan. 1968) - ed. Coleção Ouro e Prata, vols. 3 e 4, 1952

240. Júlio Verne, Da Terra à Lua, trad. Augusto de Sousa (jun. 1968)

242. Montesquieu, Grandeza e decadência dos romanos, trad. José Geraldo Vieira (ago. 1968)

244. Alexandre Dumas, Emma Lyonna, vol. 1, trad. Augusto de Sousa (out. 1968)

245. Alexandre Dumas, Emma Lyonna, vol. 2, trad. Augusto de Sousa (nov. 1968) 
246. Alexandre Dumas, Emma Lyonna, vol. 3, trad. Augusto de Sousa (dez. 1968)

247. Alexandre Dumas, Emma Lyonna, vol. 4, trad. Augusto de Sousa (jan. 1969)

248. Alexandre Dumas, Emma Lyonna, vol. 5, trad. Augusto de Sousa (fev. 1969)

258. Edgar Allan Poe, Histórias célebres, trad. Octavio Mendes Cajado (dez. 1969)

262. Júlio Verne, A jangada, vol. 1, trad. Augusto de Sousa (abr. 1970)

263. Júlio Verne, $A$ jangada, vol. 2, trad. Augusto de Sousa (maio 1970)

274. Jean Marie Andrieu, Em torno de um homem, vol. 1, trad. Juracy Daisy Marchese (abr. 1971)

275. Jean Marie Andrieu, Em torno de um homem, vol. 2, trad. Juracy Daisy Marchese (maio 1971)

281. Conde de Gobineau, Adelaide, trad. Galeão Coutinho (nov. 1971) Coleção Excelsior, Livraria Martins, 1950

\section{Conclusão}

Ao reunir dados até então dispersos e/ou incompletos sobre essas coleções e seus respectivos tradutores, esperamos dar uma pequena contribuição para a história da tradução no Brasil e facilitar o acesso de outros pesquisadores a materiais nem sempre de fácil localização.

\section{Referências bibliográficas}

A MANHÃ. De vendedor de radios a grande autor de livros para o curso primario. [Entrevista de Hildebrando Lima] 15 mar. 1947. Disponível em <http://memoria.bn.br/pdf/116408/per116408_1947_01717.pdf>. Acesso em: 27 jun. 2019.

A NoITE. Anúncio [promoção]. 16 out. 1939. Disponível em <http://memoria.bn.br/DocReader/348970_03/67759>. Acesso em: 27 jun. 2019. 
A NOITE. No mundo do mysterio e do crime. 12 set. 1934. Disponível em <http://memoria.bn.br/DocReader/348970_03/19498>. Acesso em: 27 jun. 2019.

BOA LEITURA PARA VoCÊs! Coleção Saraiva. Disponível em $<$ http://boaleituraparavoces.blogspot.com/search/label/Cole\%C3\%A7\% C3\%A30\%20Saraiva>. Acesso em: 27 jun. 2019.

CARIOCA. Anúncio [coleção completa]. 20 nov. 1937. Disponível em <http://memoria.bn.br/DocReader/830259/6653>. Acesso em: 27 jun. 2019.

DIÁRIO DA NOITE. O caso Garden [serialização]. 10 ago. 1936. Disponível em <http://memoria.bn.br/DocReader/221961_01/28096>. Acesso em: 27 jun. 2019.

DIÁRIO DE NOTÍCIAS. O homem de terno marron [serialização]. 30 dez. 1934 a 12 fev. 1935. Disponível desde $<$ http://memoria.bn.br/DocReader/093718_01/21547>. a <http://memoria.bn.br/DocReader/093718_01/22010>. Acesso em: 27 jun. 2019.

DIÁRIO DE NotícIAS. Série Negra. 4 dez. 1935. Disponível em <http://memoria.bn.br/DocReader/093718_01/25059>. Acesso em: 27 jun. 2019.

DiáRIO de Notícias. Série Nerga [sic]. Anúncio de lançamento. 13 jul. 1934. Disponível em <http://memoria.bn.br/DocReader/093718_01/19582>. Acesso em: 27 jun. 2019.

Karam, S., e Bottmann, D. A Coleção Amarela da Livraria do Globo (1931-1956). Belas Infiéis, v. 5, n. 3, Brasília (UnB), 2016, pp. 213-236. Disponível em

<http://periodicos.unb.br/index.php/belasinfieis/article/view/22286 >. Acesso em: 27 jun. 2019.

LISTAS DE LIVROS. Coleção Saraiva. Disponível em $<$ http://listasdelivros.blogspot.com/2013/12/colecao-saraiva-editorasaraiva-1948.html>. Acesso em: 27 jun. 2019.

MedeIROS E AlBUQUeRQUE, P. DE. O mundo emocionante do romance policial. Rio de Janeiro: Francisco Alves, 1979.

O CRUzeiro. Anúncio [novos lançamentos]. 30 jan. 1954. Disponível em <http://memoria.bn.br/DocReader/003581/90229>. Acesso em: 27 jun. 2019.

WIKIPEDIA. Liste des ouvrages publiés dans Le Masque. Disponível em <https://fr.wikipedia.org/wiki/Liste_des_ouvrages_publi\%C3\%A9s_dans _Le_Masque>. Acesso em: 27 jun. 2019. 


\section{Agradecimentos}

Registro aqui meus agradecimentos a José Roberto Braga Portella, Joyce Amaral de Castro, Nello Saporetti, Rogério Menezes de Moraes, Sarah Rebecca Kersley e Saulo von Randow Jr. e aos atendentes do Balaio Digital pela gentileza em prestarem várias informações pertinentes a este estudo.

Recebido em: 13/12/2018 Aceito em: 27/06/2019

Publicado em outubro de 2019 